\title{
SPECTROSCOPIC PROPERTIES OF ERBIUM IONS DOPED IN BISMUTH BORO-SILICATE GLASSES
}

\author{
SUNIL BHARDWAJ AND RAJNI SHUKLA \\ Departmen of Physics, Deenbandhu Chhotu Ram University of Science and Technology, Murthal, \\ Sonepat-131093 Haryana, India \\ sunilbhardwaj.phy@gmail.com
}

SUJATA SANGHI, ASHISH AGARWAL AND INDER PAL

Departmen of Applied Physics, Guru Jambheshware University of Science and Technology, Hisar 131093 Haryana, India

\begin{abstract}
Glasses with composition $20 \mathrm{~B}_{2} \mathrm{O}_{3} \cdot(79 \cdot 5-\mathrm{x}) \mathrm{Bi}_{2} \mathrm{O}_{3} \cdot \mathrm{xSiO}_{2}(10 \leq \mathrm{x} \leq 40)$ containing $0.5 \mathrm{~mol} \%$ of $\mathrm{Er}^{3+}$ ions were prepared by melt-quench technique. Optical absorption and fluorescence spectra were recorded at room temperature for all glass samples. Based on the Judd-Offelt theory, spectroscopic properties of $\mathrm{Er}^{3+}$ ions are discussed by changing the host glass compositions. The intensity parameters $\Omega_{2}, \Omega_{4}$, and $\Omega_{6}$ are determined by applying least square analysis method. The variation of $\Omega_{2}$ and $\Omega_{6}$ with $\mathrm{Bi}_{2} \mathrm{O}_{3}$ content has been attributed to changes in the asymmetry of the ligand field at the rare earth ion site and to the changes in the rare earth oxygen (RE-O) covalency. The variation of $\Omega_{4}$ with $\mathrm{Bi}_{2} \mathrm{O}_{3}$ content has been attributed to rigidity of the samples. Using these intensity parameters various radiative properties like spontaneous emission probability, branching ratio, radiative life time and stimulated emission cross-section of various emission lines have been evaluated. An intense green luminescence bands with maximum around $516 \mathrm{~nm}$ and $536 \mathrm{~nm}$ are assigned to the ${ }^{2} \mathrm{H}_{11 / 2} \rightarrow{ }^{4} \mathrm{I}_{15 / 2}$ and ${ }^{4} \mathrm{~S}_{3 / 2} \rightarrow{ }_{4} \mathrm{I}_{15 / 2}$ transitions respectively has been obtained.
\end{abstract}

Keywords: Spectroscopic property; Rare earth metal; Optical absorption.

\section{Introduction}

Over the past several decades, optical and spectroscopic properties of various trivalent lanthanides have been extensively investigated for various host materials to apply optical devices. After showing laser action of $\mathrm{Er}^{3+}$ by Snitzer and Woodcock in 1965 [1] considerable efforts are made on the research of $\mathrm{Er}^{3+}$ ions doped oxide glasses. Due to their rich energy level structure, the trivalent erbium doped glasses have been used as media of the up-conversion laser, wave-guide laser, and erbium-doped fiber amplifier (EDFA) which is one of the key elements used in the wavelength-division-multiplexing (WDM) network for optical communication. Recently, much attention has been given to the research of the $\mathrm{Er}^{3+}$ ions doped glasses [2-4] due to the $1.5 \mu \mathrm{m}$ emission from the ${ }^{4} \mathrm{I}_{13 / 2} \rightarrow{ }^{4} \mathrm{I}_{15 / 2}$ transition is eye safe and located in the optical third communication window where the losses are minimum. The most stable ionization state is the trivalent one, with $5 s \& 5 p$ electrons remaining untouched and acting to screen the energy levels of the $4 f$ 
electrons from the effect of surrounding environment. The transition probability between $4 \mathrm{f}$ states, however are sensitive to the ions surrounding the rare earth ions.

In general, the optical and spectroscopic properties are strongly dependent on host materials. Many potential host materials for rare earth ions have been developed. It was found that the oxide glasses have small absorption coefficient, high chemical and thermal durability, therefore they are suitable material for technology applications [5-6]. Silicate glasses are chemically durable, thermally stable and optically transparent at the excitation and lasing wavelength. Bismuth oxide glasses are more suitable due to its high refractive index, low phonon energy and good chemical suitability [7-8]. The efforts to improve quantum efficiency of the luminescence bands have paid attention to heavy metal host materials [9-10]. The Judd-Ofelt theory [11-12] is usually adopted to calculate, by assuming certain approximation, transitions probability from the data of absorption crosssection of several f-f transitions. According to this theory, the strength of an $\mathrm{f}-\mathrm{f}$ transitions may be expressed by the sum of the products of three intensities parameters $\Omega_{\lambda}(\lambda=2,4,6)$ times the squared matrix elements $\mathrm{U}^{(\mathrm{t})}$ between the initial J-states and the terminal J* state. Once the phenomenological parameters $\Omega_{\lambda}$ have been calculated, it is possible to derive the strength of any absorption or emission transmission, as well as the stimulated cross-section, the fluorescence branching ratio from level $\mathrm{J}$ to $\mathrm{J}^{*}$, and the radiative life time of an excited level. Such spectral studies give valuable information about the structure and bonding in glass and radiative and non radiative properties of rare earth ions doped in glass matrix. This information is essentially required while developing new optical devices [13].

Oxide glasses are stable hosts for obtaining efficient luminescence in rare earth ions. Therefore, the purpose of the present study is to introduce the upgraded lasing material by including the heavy metals $\mathrm{Bi}_{2} \mathrm{O}_{3}$ in silicate glasses using Judd-Ofelt theory.

\section{Theoretical Details}

The Judd-Ofelt [11-12] parameters $\Omega_{\lambda}(\lambda=2,4,6)$ can be determined from the experimental ground state oscillator strength $\left(f_{\text {expt }}\right)$ of the absorption spectral transitions via an integration of the absorption coefficients for each band according to the following equation:

$$
f_{\text {expt. }}=4.318 \times \int \varepsilon(v) d v
$$

where $\varepsilon(v)$ is the molar extinction coefficient at average energy $(v)$ in $\mathrm{cm}^{-1}$. The measured line strength is used to calculate the intensity parameters $\Omega_{\lambda}$ by solving a set of equations for the corresponding transitions between initial to terminal manifold ( $\Psi J \rightarrow \Psi^{\prime} J^{\prime}$ ) expressed by calculated oscillator strengths $\left(f_{c a l}\right)$ and is given by

$$
f_{c a l}\left(\Psi J ; \Psi^{\prime} J^{\prime}\right)=\frac{8 \pi^{2} m c v}{3 h(2 J+1)}\left[\frac{\left(n^{2}+2\right)^{2}}{9 n}\right] \times \sum_{\lambda=2,4,6} \Omega_{\lambda}\left(\Psi J\left\|U^{\lambda}\right\| \Psi^{\prime} J^{\prime}\right)^{2}
$$


where $\left(n^{2}+2\right)^{2} / 9 n$ is a factor for the effective field at the well-localized center in a medium of isotropic refractive index, $\mathrm{m}$ is the mass of electron, $\mathrm{c}$ is the velocity of light in vacuum, $\mathrm{h}$ is the Planck's constant, $\mathrm{n}$ is the refractive index of glass, $v$ is the frequency of the $\Psi J \rightarrow \Psi^{\prime} J^{\prime}$ transition, $\Omega_{\lambda}(\lambda=2,4,6)$ are the J-O intensity parameters and $\left\|U^{\lambda}\right\|$ are the doubly reduced matrix elements of the unit tensor operator of the rank $\lambda=2,4$ and 6 which are calculated from the intermediate coupling approximation for a transition $\Psi J \rightarrow \Psi^{\prime} J^{\prime}$.

In order to determine the accuracy of the intensity parameters, the root-mean-square deviation $\left(\delta_{\mathrm{RMS}}\right)$ is also calculated using the relation .

$$
\delta_{R M S}=\left[\frac{\Sigma\left(f_{c a l}-f_{\exp t}\right)^{2}}{\Sigma f_{\exp t}^{2}}\right]^{1 / 2}
$$

Where summation is taken over the bands used to calculate $\Omega_{\lambda}$ parameters.

The spontaneous emission probability for a transition from an initial state ( $\Psi J$ ) to a particular final state $\left(\Psi^{\prime} J^{\prime}\right)$ is given by

$$
A_{R}\left(\Psi J ; \Psi^{\prime} J^{\prime}\right)=\frac{64 \pi^{4} v^{3}}{3 h(2 J+1)}\left[\frac{n\left(n^{2}+2\right)^{2}}{9} S_{e d}+n^{3} S_{m d}\right]
$$

where $S_{e d}$ and $S_{m d}$ are electric and magnetic dipole line strengths, respectively. The selection rules for the electric dipole transitions $S_{\text {ed }}$ from the $f$-configuration mixing include $\Delta l= \pm 1, \Delta S=0,|\Delta L|$ and $|\Delta J| \leq 6$. The total radiative transition probability $\left(A_{T}\right)$ of an excited state is given by the sum of the $A_{R}\left(\Psi J ; \Psi^{\prime} J^{\prime}\right)$ terms calculated over all the terminal states and is related to radiative life time $\left(\tau_{\mathrm{R}}\right)$ as

$$
\frac{1}{\tau_{R}}=A_{T}(\Psi J)=\sum_{\Psi^{\prime} J^{\prime}} A_{R}\left(\Psi J ; \Psi^{\prime} J^{\prime}\right)
$$

And the branching ratio is given by

$$
\beta_{R}\left(\Psi J ; \Psi^{\prime} J^{\prime}\right)=\frac{A_{R}\left(\Psi J ; \Psi^{\prime} J^{\prime}\right)}{A_{T}(\Psi J)}
$$

The peak stimulated emission cross-section, $\sigma_{e}\left(\lambda_{p}\right)$, is an essential parameter to predict the laser performance of the glass and can be determined using the following expression

$$
\sigma_{e}\left(\lambda_{p}\right)=\frac{\lambda_{p}^{4}}{8 \pi c n^{2} \Delta \lambda_{e f f}} A_{R}\left(\Psi J ; \Psi^{\prime} J^{\prime}\right)
$$

where $\lambda_{p}$ is the wavelength of the fluorescence peak and $\Delta \lambda_{\text {eff }}$ is the line width obtained by dividing the area of the emission band by its average height. The large value of 
stimulated emission cross-section and high branching ratio determine the suitability of the materials for good optical devices.

\section{Experimental}

Glasses having compositions $20 \mathrm{~B}_{2} \mathrm{O}_{3} \cdot(79 \cdot 5-\mathrm{x}) \mathrm{Bi}_{2} \mathrm{O}_{3} \cdot \mathrm{xSiO}_{2}(10 \leq \mathrm{x} \leq 40, \mathrm{~mol} \%)$ doped with $0.5 \mathrm{~mol} \%$ of $\mathrm{Er}^{3+}$ ions were prepared by melt quench technique. Appropriate amount of AR grade chemicals $\left(\mathrm{B}_{2} \mathrm{O}_{3}, \mathrm{Bi}_{2} \mathrm{O}_{3}, \mathrm{SiO}_{2}\right.$ and $\left.\mathrm{Er}_{2} \mathrm{O}_{3}\right)$ having purity above $99.99 \%$ were weighed on $0.001 \%$ accuracy and mixed thoroughly. The raw mixed materials were melted in a muffle furnace in air (at $1150{ }^{\circ} \mathrm{C}$ for $40 \mathrm{~min}$ ). The crucible was shaken frequently after every 10 minutes for the homogeneous mixing of all the constituents. The melt was quenched at room temperature by pouring between two stainless steel plates. The quenched samples were annealed to minimize the internal strain and then allowed to cool slowly to room temperature. The samples were polished for spectral and other investigations. The amorphous nature of the glasses was confirmed by recording the $\mathrm{X}$ ray diffraction pattern using Mini Flex Desktop X-ray Difractometer with $\mathrm{Cu}-\mathrm{K} \alpha$ line of wavelength at the scanning rate of $2^{\circ} / \mathrm{min}$ and $2 \theta$ was varied from $10^{\circ}$ to $80^{\circ}$.

The refractive index (n) of the prepared samples was measured by the Brewster angle method using He-Ne laser $(633 \mathrm{~nm})$. The density $\left(D_{g}\right)$ of all the glasses was measured by using Archimedes principle with xylene as immersing liquid. The relation used is

$$
\mathrm{D}_{\mathrm{g}}\left(\mathrm{gm} / \mathrm{cm}^{3}\right)=\frac{\mathrm{W}_{\mathrm{a}}}{\mathrm{W}_{\mathrm{a}}-\mathrm{W}_{\mathrm{b}}} D_{x}
$$

Where $\mathrm{W}_{\mathrm{a}}$ is the weight of glass sample in air, $\mathrm{W}_{\mathrm{b}}$ is the weight of glass sample when immersed in xylene and $D_{x}$ is the density of xylene $\left(0.86 \mathrm{gm} / \mathrm{cm}^{3}\right)$.

The Optical absorption spectra of all the polished samples were recorded on a VarianCarry 5000 spectrophotometer in the range $300-3200 \mathrm{~nm}$. The emission spectra were recorded using Fluoro-max-3 Fluorimeter with Xe arc lamp as the excitation source at wavelength of $800 \mathrm{~nm}$.

\section{Result and Discussion}

The optical absorption spectrum of BBSE1 is shown in Fig. 1. From these spectra, absorption bands at $488,520,538,650,816$ and $976 \mathrm{~nm}$ are observed, which predict the $\mathrm{Er}^{3+}$ ions transition from the ground state ${ }^{4} \mathrm{I}_{15 / 2}$ to various excited states within $4 \mathrm{f}$ shell which were assigned as ${ }^{4} \mathrm{~F}_{7 / 2},{ }^{2} \mathrm{H}_{11 / 2},{ }^{4} \mathrm{~S}_{3 / 2},{ }^{4} \mathrm{~F}_{9 / 2},{ }^{4} \mathrm{I}_{9 / 2}$, and ${ }^{4} \mathrm{I}_{11 / 2}$ respectively. The experimental and calculated values of oscillator strength are presented in Table1. 


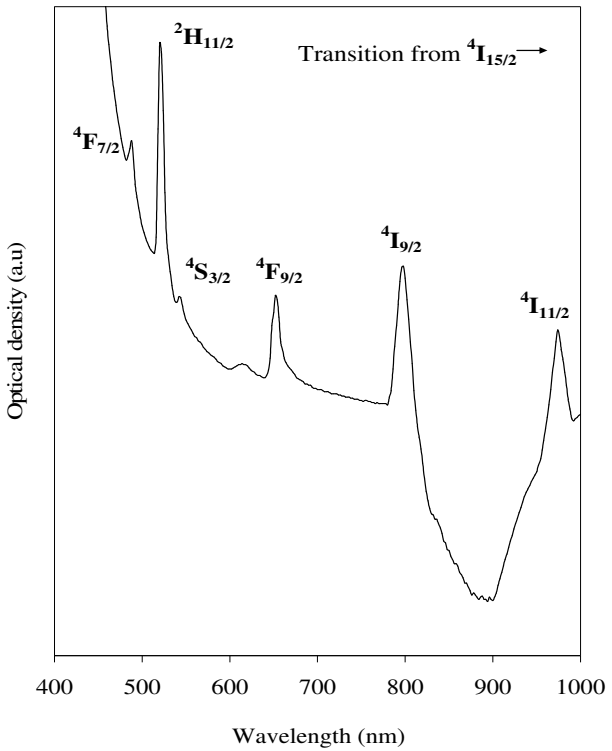

FIG. 1. Optical absorption of BBSE1 glass

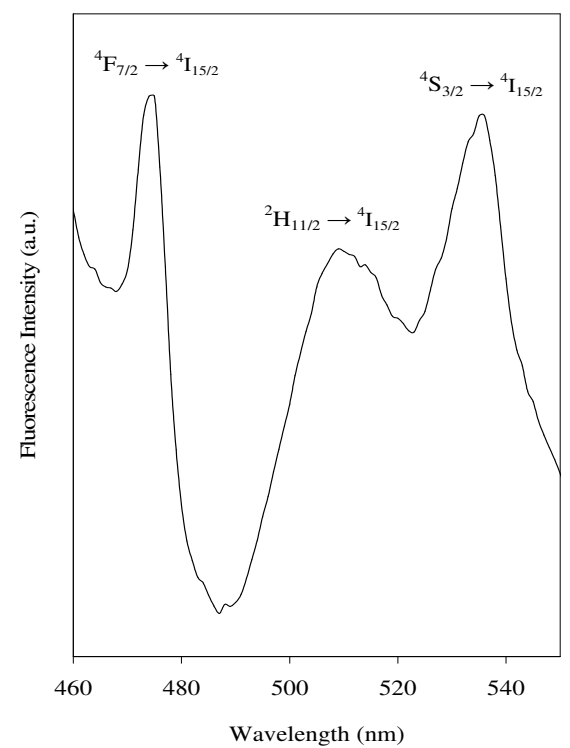

FIG. 2. Fluorescence spectra of BBSE1 glass

Table 1. Oscillator strength ( $\mathrm{f} \times 10^{-6}$ ) for the transitions from ground level ${ }^{6} \mathrm{I}_{5 / 2}$ and root mean square $\left(\delta_{\mathrm{RMS}}\right)$ of various $\mathrm{Er}^{3+}$ doped BBSE glasses.

\begin{tabular}{|c|c|c|c|c|c|c|c|c|c|}
\hline \multirow{2}{*}{\multicolumn{2}{|c|}{$\begin{array}{l}\text { Transitions } \lambda \\
{ }^{4} \mathbf{I}_{\mathbf{1 5} / \mathbf{2}} \rightarrow\end{array}$}} & \multicolumn{2}{|c|}{ BBSE1 } & \multicolumn{2}{|c|}{ BBSE2 } & \multicolumn{2}{|c|}{ BBSE3 } & \multicolumn{2}{|c|}{ BBSE4 } \\
\hline & & fex & fcal & Fexp & fcal & fexp & fcal & Fexp & fcal \\
\hline${ }^{4} \mathrm{~F}_{7 / 2}$ & 488 & 0.80 & 1.02 & 0.73 & 0.87 & 0.70 & 0.92 & 0.61 & 0.54 \\
\hline${ }^{2} \mathrm{H}_{11 / 2}$ & 520 & 2.37 & 3.02 & 1.72 & 2.25 & 1.57 & 1.64 & 1.08 & 0.87 \\
\hline${ }^{4} \mathrm{~F}_{9 / 2}$ & 650 & 1.34 & 1.83 & 1.34 & 1.41 & 1.52 & 0.98 & 1.26 & 1.09 \\
\hline${ }^{4} \mathbf{I}_{9 / 2}$ & 816 & 2.72 & 3.14 & 2.36 & 2.68 & 1.91 & 1.80 & 1.57 & 0.93 \\
\hline${ }^{4} \mathrm{I}_{11 / 2}$ & 976 & 1.39 & 0.99 & 2.93 & 2.80 & 0.97 & 0.89 & 1.29 & 1.59 \\
\hline \multicolumn{2}{|c|}{$\delta_{\mathrm{RMS}}\left(10^{-6}\right)$} & \multicolumn{2}{|l|}{0.97} & \multicolumn{2}{|l|}{1.32} & \multicolumn{2}{|l|}{1.17} & \multicolumn{2}{|l|}{1.32} \\
\hline
\end{tabular}

According to the Judd-Ofelt theory, the effect of the crystal field can be described by three intensity parameters $\Omega_{\lambda}(\lambda=2,4,6)$. These parameters are obtained from the experimental oscillator strengths and the calculated double reduced matrix elements by using least square analysis method [14]. The variation of $\Omega_{2}$ with $\mathrm{Bi}_{2} \mathrm{O}_{3}$ content has been attributed to changes in the asymmetry of the ligand field at the rare earth ion site and to the changes in their rare earth oxygen (RE-O) covalency [15]. The shift in the hypersensitive band shows that the covalency of the RE-O bond decreases with decrease of $\mathrm{Bi}_{2} \mathrm{O}_{3}$ content, and it is attributed to the increased interaction between the rare earth ions and the non-bridging oxygen's (NBO's). Therefore the covalency of the rare-earth oxygen decreases with the increase in $\mathrm{SiO} 2$ content in the host glasses. 
Table 2 Refractive index (n), Judd-Ofelt intensity parameters $\left(\Omega_{2}, \Omega_{4}, \Omega_{6}\right)$ and SQF of various $\mathrm{Er}^{3+}$ doped BBSE glasses.

\begin{tabular}{lllll}
\hline Intensity & BBSE1 & BBSE2 & BBSE3 & BBSE4 \\
\hline $\mathrm{n}$ & 2.12 & 1.84 & 1.73 & 1.68 \\
$\Omega_{2}\left(10^{-20} \mathrm{~cm}^{2}\right)$ & 2.32 & 2.83 & 3.22 & 3.69 \\
$\Omega_{4}\left(10^{-20} \mathrm{~cm}^{2}\right)$ & 1.42 & 1.32 & 1.48 & 1.56 \\
$\Omega_{6}\left(10^{-20} \mathrm{~cm}^{2}\right)$ & 1.17 & 1.22 & 1.11 & 1.43 \\
$(\mathrm{SQF}) \Omega_{4 /} \Omega_{6}$ & 1.21 & 1.08 & 1.33 & 1.09 \\
\hline
\end{tabular}

Where as the intensity parameters $\Omega_{4}$ and $\Omega_{6}$ are related to the rigidity of the host [16]. A measure of the accuracy of the fitted values of the $\Omega_{\lambda}$ parameters are given by $\delta_{\mathrm{RMS}}$ deviation which is also given in table 1 .

Fig. 2, shows three peaks of emission spectrum at $475,516,536 \mathrm{~nm}$ that assigned the following emission transitions ${ }^{4} \mathrm{~F}_{7 / 2} \rightarrow{ }^{4} \mathrm{I}_{15 / 2},{ }^{2} \mathrm{H}_{11 / 2} \rightarrow{ }^{4} \mathrm{I}_{15 / 2},{ }^{4} \mathrm{~S}_{3 / 2} \rightarrow{ }^{4} \mathrm{I}_{15 / 2}$ respectively.

Table 3 The peak wavelength $\left(\lambda_{\mathrm{p}}\right)$, radiative transition probability $\left(\mathrm{A}_{\mathrm{rad}}\right)$, branching ratio $\left(\beta_{\mathrm{r}}\right)$, stimulated emission cross-section $(\sigma)$, total radiative transition probability $\left(\mathrm{A}_{\mathrm{T}}\right)$ and radiative life time $\left(\tau_{\mathrm{r}}\right)$ of $\mathrm{Er}^{3+}$ ion doped BBSE glasses

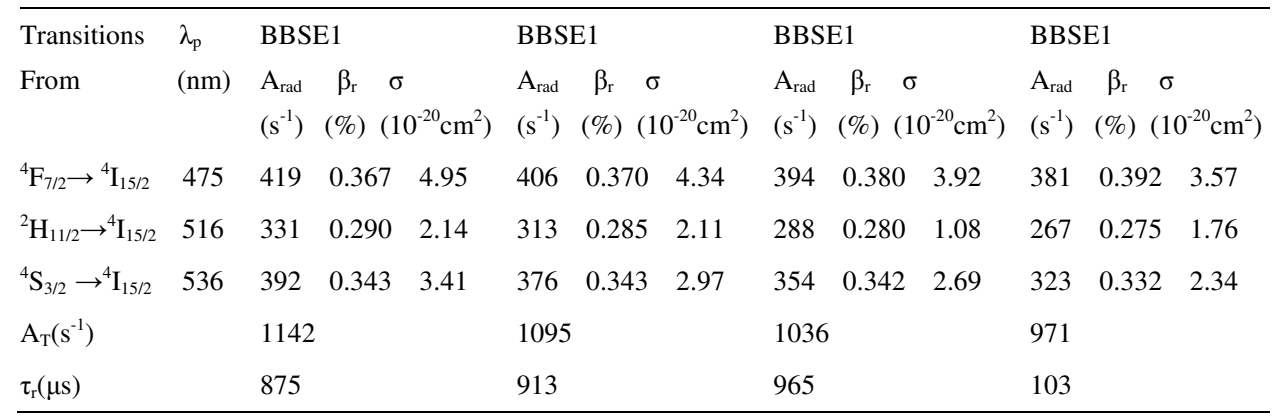

From table 3 , it is observed that the value of stimulated emission cross-section $(\sigma)$ decreases with the decrease in $\mathrm{Bi}_{2} \mathrm{O}_{3}$ content in the host glass. The trend observed in the

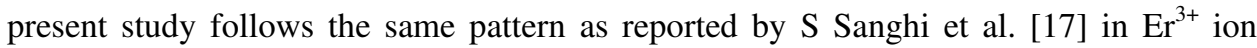
doped zinc bismuth borate glass.

From the figure 2 two green luminescence bands with maximum around $516 \mathrm{~nm}$ and $536 \mathrm{~nm}$ are assigned to the ${ }^{2} \mathrm{H}_{11 / 2} \rightarrow{ }^{4} \mathrm{I}_{15 / 2}$ and ${ }^{4} \mathrm{~S}_{3 / 2} \rightarrow{ }^{4} \mathrm{I}_{15 / 2}$ transitions respectively. Another emission band is identified as due to ${ }^{4} \mathrm{~F}_{7 / 2} \rightarrow{ }^{4} \mathrm{I}_{15 / 2}$ electronic transition. The most intense emission (easily seen by naked eyes) corresponds to the green emission from the ${ }^{4} \mathrm{~S}_{3 / 2}$ level. Further-more, these emissions are in agreement with previous investigations on erbium-doped glasses [18-20]. The high values of stimulated emission cross-section suggest that the prepared glasses are potential candidates for the lasing host materials and for low threshold, high gain applications. 


\section{Conclusion}

The refractive index of the glass reduces from 2.12 to 1.68 with the decrease in $\mathrm{Bi}_{2} \mathrm{O}_{3} /$ $\mathrm{SiO}_{2}$ ratio. The spectroscopic properties of $\mathrm{Er}^{3+}$ doped glass has been analyzed on the basis of Judd-Ofelt theory. The covalent nature of the prepared glass decreases with the decrease in $\mathrm{Bi}_{2} \mathrm{O}_{3}$ content in the host glass. The branching ratio for the transition ${ }^{4} \mathrm{~F}_{7 / 2} \rightarrow$ ${ }^{4} \mathrm{I}_{15 / 2}$ is $40 \%$ therefore the radiative transition probability is high as $419 \mathrm{~s}^{-1}$ as shown in Table 3. From here it concluded that the prepared glasses are suitable host for the lasing materials. It shows lasing emission in the visible range.

\section{References}

1. E. Snitzer, R. Woodcock, Appl. Phys. Lett. 6, 45 (1965).

2. B. Viana, M. Palazzi, and O. LeFol, Journal of Non-Crystalline Solids 215, 96-102 (1997).

3. L. Boehm, R. Reisfeld, N. Sepctor, Journal of Solid State Chemistry. 28, 75-79 (1979).

4. B.T. Stone, K.L. Bray, Journal of Non-Crystalline Solids. 197, 136-144 (1996).

5. Y. D. Huang, M. Mortier, F. Auzel, Opt. Mater. 15, 243 (2001).

6. H. Choi, A. Margaryan, F. G. Shi, Journal of Luminescence. 114, 167-177 (2005).

7. I. Operea, H. Hesse, K. Betzler. Optical Materials 26(3) 235-237 (2004).

8. P. Becker, Crystal Research and Technololgy. $174-78$ (2003).

9. X. Zou, T. Izumitani J. Non-Cryst. Solids 162 (1) 68-80 (1993).

10. S. Tanabe, T Ohayagi, N Soga, T Honda Phys. Rev. B46 3305-3309 (1992).

11. B.R. Judd, Phy. Rev. 127 750-761 (1962).

12. G.S. Ofelt, Chem Phys. 37 511-519 (1962).

13. A.A. Kamniskii, Laser crystals, second ed. Springer, Berlin. (1990) 252-253.

14. W.F. Krupke, IEEE J. Quantum electron 10 450-457(1974).

15. S. Tanabe, T. Ohagi, N. Soga, T. Hanada, Phys. Rev.B 46, 3305 (1992)

16. L.R.P. Kassab, A.de O. Preto, W.Lozano, F.X.de Sa, G.S. Maciel, J. Non-Cryst. Solids 43-45, 3468 (2005)

17. S. Sanghi, I. Pal, A. Agarwal and M.P. Agarwal, Spectra. Chemica. Acta Part A 83, 94, (2011).

18. R. Balda, A. J G. Adeva, J. Fernandez and J. M. Fdez-Navarro, J. Opt. Soc. Am. B 21, 744 (2004)

19. Z. Pan, S. H. Morgan, A. Loper, V. King, B. H. Long and W. E. Collins, J. Appl. Phys., 77 (9), 4688, (1995)

20. Z. Pan, S. H. Morgan, K. Dyer and A. Ueda, J. Appl. Phys., 79 (12), 8906, (1996) 